\title{
Six-month follow-up of functional status in discharged patients with coronavirus disease 2019
}

Hou-wei Du ${ }^{1,2 \dagger}$, Shuang-fang Fang ${ }^{1,2 \dagger}$, Sang-ru Wu ${ }^{1,2+}$, Xiao-ling Chen ${ }^{3 \dagger}$, Jun-nian Chen ${ }^{4}$, Yi-xian Zhang $^{5}$, Hua-yao Huang ${ }^{5}$, Han-han Lei ${ }^{1,2}$, Rong-hua Chen ${ }^{1,2}$, Xiao-bin Pan ${ }^{6}$, Xiao-qing Li ${ }^{7}$, Pin-cang Xia ${ }^{7}$, Zhen-yang Zheng ${ }^{1,2}$, Ling-Luo ${ }^{1,2}$, Hai-long Lin ${ }^{8}$, Li-min Chen ${ }^{9}$ and Nan Liu ${ }^{1,5^{*}}$ (I) on behalf of Fujian Medical Team Support Wuhan for COVID19

\begin{abstract}
Background: The long-term functional outcome of discharged patients with coronavirus disease 2019 (COVID-19) remains unresolved. We aimed to describe a 6-month follow-up of functional status of COVID-19 survivors.

Methods: We reviewed the data of COVID-19 patients who had been consecutively admitted to the Tumor Center of Union Hospital (Wuhan, China) between 15 February and 14 March 2020. We quantified a 6-month functional outcome reflecting symptoms and disability in COVID-19 survivors using a post-COVID-19 functional status scale ranging from 0 to 4 (PCFS). We examined the risk factors for the incomplete functional status defined as a PCFS $>0$ at a 6-month follow-up after discharge.

Results: We included a total of 95 COVID-19 survivors with a median age of 62 (IQR 53-69) who had a complete functional status (PCFS grade 0) at baseline in this retrospective observational study. At 6-month follow-up, 67 (70.5\%) patients had a complete functional outcome (grade 0), 9 (9.5\%) had a negligible limited function (grade 1), 12 (12.6\%) had a mild limited function (grade 2), 7 (7.4\%) had moderate limited function (grade 3). Univariable logistic regression analysis showed a significant association between the onset symptoms of muscle or joint pain and an increased risk of incomplete function (unadjusted $\mathrm{OR} 4.06,95 \% \mathrm{Cl} 1.33-12.37$ ). This association remained after adjustment for age and admission delay (adjusted OR 3.39, 95\% Cl 1.06-10.81, $\mathrm{p}=0.039$ ).
\end{abstract}

Conclusions: A small proportion of discharged COVID-19 patients may have an incomplete functional outcome at a 6-month follow-up; intervention strategies are required.

Keywords: Coronavirus disease 2019, Functional outcome, Follow-up

*Correspondence: xieheliunan1984@fjmu.edu.cn

†Hou-wei Du, Shuang-fang Fang, Sang-ru Wu, and Xiao-ling Chen have contributed equally to this work.

${ }^{1}$ Department of Neurology, Fujian Medical University Union Hospital, 29

Xinquan Road, Gulou District, Fuzhou 35000, China

Full list of author information is available at the end of the article

\section{Background}

Coronavirus disease 2019 (COVID-19) due to severe acute respiratory syndrome coronavirus 2 (SARS-CoV-2) infection was firstly reported in Wuhan, China in December 2019 [1]. As of 9 September 2021, the COVID-19 pandemic has spread worldwide, affecting more than 220 million people and killing over four millions lives [2]. Aggregating studies have shown that most SARS$\mathrm{CoV}-2$ infection was mild and moderate, which seems to 
have a positive recovery rate [3-5]. Previous studies with short-term follow-up data showed that a few discharged COVID-19 patients were re-positive for SARS-nCoV-2 detected by reverse transcription-polymerase chain reaction (RT-PCR) analysis [6, 7]. Moreover, in addition to physical damage, some COVID-19 patients may suffer from psychological impairment including sleep disorder, depression and anxiety after discharge [8,9]. Previous studies also showed that discharged COVID-19 patients might have incompletely absorbed computed tomography $(\mathrm{CT})$ findings, and some may develop residual pulmonary fibrosis $[10,11]$. Moreover, a retrospective study showed that more than half of the COVID-19 patients in the early convalescence phase had impaired diffusingcapacity, lower respiratory muscle strength, and lung imaging abnormalities [12]. Patients with other coronavirus infection like severe acute respiratory syndrome (SARS) or Middle East respiratory syndrome (MERS) may have long-term persistent radiographic abnormalities in their lungs $[13,14]$. It is reasonable to imagine that some COVID-19 patients may have adverse functional outcomes despite recovery. To our knowledge, the follow-up advice for those testing positive for COVID-19 is lacking, and the long-term functional status in COVID19 survivors remains poorly understood. We aimed to describe a six-month follow-up of the functional status of COVID-19 patients after discharge in this retrospective cohort study.

\section{Methods}

\section{Study design, participants and data collection}

In this retrospective single-center observational study, we collected the demographic and clinical data of laboratory-confirmed COVID-19 patients who had been consecutively admitted to the Tumor Center of Union Hospital (Wuhan, China) between 15 February and 14 March 2020. The extraction and analysis of baseline data regarding demographic and clinical characteristics were documented in our previous published literature [15,
16]. Severe COVID-19 was defined as fever or suspected respiratory infection, plus one of: respiratory rate $>30$ breaths/min; severe respiratory distress; or $\mathrm{SPO}_{2} \leq 93 \%$ on room air based on the interim guidance of the World Health Organization [17]. The discharge criteria were as follows: 1 . Normal body temperature for more than three days; 2 . Significantly improved respiratory symptoms, 3. Substantial lung inflammation absorption on chest CT image, 4. Two consecutive negative results of nucleic acid tests for SARS-CoV-2 from the respiratory samples separated by at least one day [18]. We obtained and clarified data by direct communication with attending physicians and the healthcare providers when data were missing or uncertain from the medical records. We excluded patients if they did not undergo a post-COVID-19 functional status scale (PCFS) interview at six-month followup after discharge or had a PCFS $>0$ at baseline (one month before the onset of COVID-19 symptoms).

\section{Follow-up}

Patients were followed-up at a 6-month after discharge. The PCFS was designed as a measure to focus on relevant aspects of daily life during follow-up in COVID-19 patients $[19,20]$. Briefly, we asked four questions to our participants or their caregivers: 1. Can you live alone without any assistance from another person? 2. Are there any duties and/or activities at home or at work which you are no longer able to perform yourself? 3. Do you suffer from symptoms, pain, depression or anxiety? 4. Do you need to avoid or reduce duties and/or activities or spread these over time? Based on the answers to these questions, the PFCS grades $(0,1,2,3,4)$ were generated (Table 1$)$. Grade 0 reflects the absence of any functional limitation, grade 1 and 2 mirror negligible to mild functional limitation, while grade 3 and 4 reflect moderate to severe limitation of functional status [20]. Two trained authors (S.F. and H.L.) who were blinded to the baseline routine clinical data performed the structured interview with participants by one telephone (with 'hand-free' function)

Table 1 Post-COVID-19 Functional Status Scale

\begin{tabular}{ll}
\hline PCFS scale grade & Description \\
\hline $\begin{array}{l}\text { 0. No functional limitations } \\
\text { 1. Negligible functional limitations }\end{array}$ & $\begin{array}{l}\text { No symptoms, pain, depression or anxiety } \\
\text { toms, pain, depression or anxiety }\end{array}$ \\
$\begin{array}{ll}\text { 2. Slight functional limitations } \\
\text { Usual duties/activities at home or at work are carried out at a lower level of intensity or are occasionally avoided } \\
\text { due to symptoms, pain, depression or anxiety }\end{array}$ \\
$\begin{array}{l}\text { Usual duties/activities at home or at work have been structurally modified (reduced) due to symptoms, pain, } \\
\text { depression or anxiety }\end{array}$ \\
$\begin{array}{l}\text { Assistance needed in activities of daily living due to symptoms, pain, depression or anxiety: nursing care and } \\
\text { attention are required }\end{array}$
\end{tabular}


interview in a quiet room at the same time at six-month after discharge, based on the PCFS manual (version May 2020) [20]. In case of disagreement, a consensus was reached after team discussion. We assessed inter-rater agreement on a random sample using Cohen's Kappa coefficient.

\section{Outcomes}

Our primary outcome was the functional status of the COVID-19 patients at a six-month follow-up by using a PCFS interview [19].

\section{Statistics}

We summarized continuous data with mean value with standard deviations or median value with interquartile range (IQR), and categorized data as counts with percentages. We used the t-test or Mann-Whitney test to compare the differences in continuous variables, and the chi-square test or Fisher's exact test to compare the differences in categorical variables as appropriate. To permit a comparison, we dichotomized patients into complete $(\mathrm{PCFS}=0)$ and incomplete $(\mathrm{PCFS}>0)$ functional status at six-months follow-up after discharge. We included potentially significant variables if $\mathrm{p} \leq 0.2$ by univariable analysis into the multivariable logistic regression model, to investigate the factors for the incomplete functional $(\mathrm{PCFS}>0)$. All statistics were performed using SPSS for windows 22.0 (IBM, Inc, USA).

\section{Results}

We consecutively enrolled a total of 164 patients with laboratory-confirmed COVID-19 between 15 February and 14 March 2020. After excluding seven non-survivors and 53 lost to follow-up or did not undergo the PCFS interview, 104 patients (53 [50.9\%] male) with a median age of 62 (IQR 54-70] participated in the followup. Patients with and without the PCFS interview were similar in age (63 [54-70] vs 62 [52-69], $\mathrm{p}=0.493)$, to be male (53 [51.0\%] vs 24 [45.3\%], $\mathrm{p}=0.501)$, and admission delay $(13$ [7-20] days vs 14 [9-21], $\mathrm{p}=0.157)$. After further excluding three (2.9\%) patients with grade 3 and six $(5.8 \%)$ patients with grade 4 at baseline, we included 95 patients with a baseline $\mathrm{PCFS}=0$ in the final analysis (Fig. 1).

Table 2 shows the demographics and clinical characteristics of the study population. The inter-rater reliability

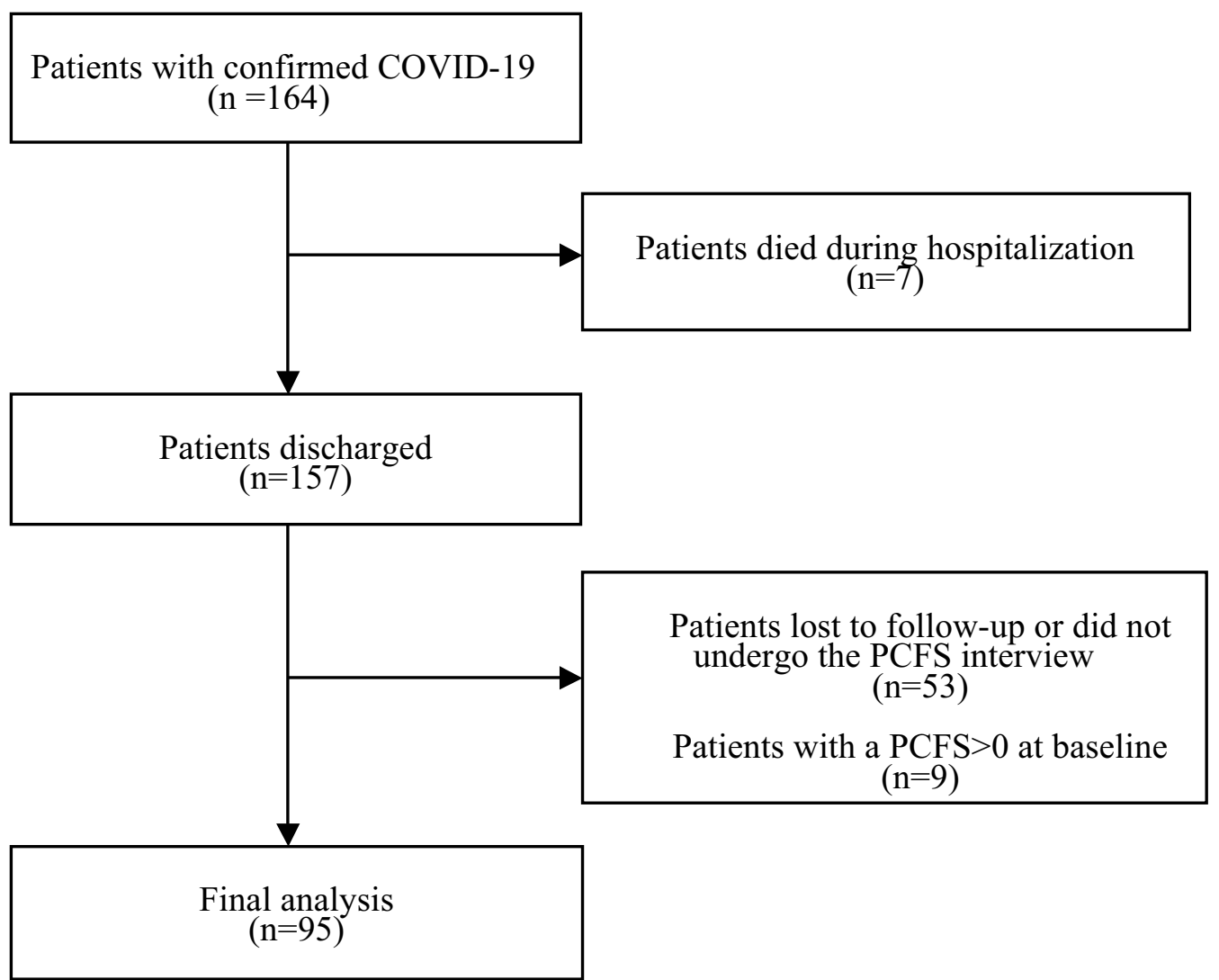

Fig. 1 Flow chart of patients selection. COVID-19 coronavirus disease 2019. PCFS post-COVID-19 functional status scale 
Table 2 Baseline characteristics of study participants

\begin{tabular}{|c|c|}
\hline & $\begin{array}{l}\text { Total } \\
(n=95)\end{array}$ \\
\hline Age, (y) median, (IQR) & $62(53-69)$ \\
\hline Male, n (\%) & $50(52.6)$ \\
\hline Current smoker, n (\%) & $10(10.5)$ \\
\hline Regular drinker, n (\%) & $2(2.1)$ \\
\hline Hypertension, n (\%) & $27(28.4)$ \\
\hline Diabetes, n (\%) & $14(14.7)$ \\
\hline COPD, n (\%) & $6(6.3)$ \\
\hline Cardio-cerebrovascular disease, n (\%) & $16(12.7)$ \\
\hline Tumor, n (\%) & $7(7.4)$ \\
\hline Immunosuppressives, n (\%) & $2(2.1)$ \\
\hline Renal impairment, n (\%) & $11(11.6)$ \\
\hline Wet market exposure, n (\%) & $1(1.1)$ \\
\hline \multicolumn{2}{|l|}{ Clinical symptoms } \\
\hline Fever, n (\%) & $69(72.6)$ \\
\hline Dry cough, n, (\%) & $62(65.3)$ \\
\hline Productive cough, n (\%) & $11(11.6)$ \\
\hline Fatigue, n (\%) & $35(36.8)$ \\
\hline Muscle or joint ache, n (\%) & $16(16.8)$ \\
\hline Thoracalgia, n (\%) & $16(16.8)$ \\
\hline Sore throat, n (\%) & $14(14.7)$ \\
\hline Diarrhea, n (\%) & $9(9.5)$ \\
\hline Catarrh, n (\%) & $5(5.3)$ \\
\hline Anorexia, n (\%) & $28(29.5)$ \\
\hline Short of breath, $\mathrm{n}(\%)$ & $33(34.7)$ \\
\hline Headache, n (\%) & $14(14.7)$ \\
\hline \multicolumn{2}{|l|}{ Routine blood examinations } \\
\hline Decreased leucocytes, n (\%) & $5(5.3)$ \\
\hline Decreased lymphocytes, n (\%) & $27(28.4)$ \\
\hline Decreased hemoglobin, n (\%) & $24(25.3)$ \\
\hline Decreased platelets, n (\%) & $5(5.3)$ \\
\hline ALT or AST $>40 \mathrm{U} / \mathrm{L}$ & $37(29.4)$ \\
\hline \multicolumn{2}{|l|}{ Chest CT findings, n (\%) } \\
\hline Unilateral pneumonia, n (\%) & $16(16.8)$ \\
\hline Bilateral pneumonia, n (\%) & $55(57.9)$ \\
\hline Multiple mottling and ground-glass opacity, n (\%) & $24(25.3)$ \\
\hline Treated with steroid, n (\%) & $10(10.5)$ \\
\hline Antiviral, n (\%) & $93(97.9)$ \\
\hline Severe COVID-19, n (\%) & $13(13.7)$ \\
\hline Admission delay, (day) median, (IQR) & $14[8-21]$ \\
\hline
\end{tabular}

Decreased means below the lower limit of the normal range. Leucocytes ( $\times 10^{9} / \mathrm{L}$; normal range 3.5-9.5); Lymphocytes $\left(\times 10^{9} / \mathrm{L}\right.$; normal range $\left.1.1-3.2\right)$; Platelets $\left(\times 10^{9} / \mathrm{L}\right.$; normal range $\left.125.0-350.0\right)$; Hemoglobin ( $/ \mathrm{L}$; normal range 130.0-175.0)

COVID-19 coronavirus disease 2019; SD standard deviation; COPD chronic obstructive pulmonary disease; IQR interquartile range; ALT alanine transaminase (U/L; normal range 0-40); AST alanine aminotransferase (U/L; normal range 0-40); CT computed tomography for baseline PCFS interview was 0.68 (95\% CI 0.46-0.90); for PCFS interview 6-month after discharge 0.79 (95\% CI 0.65-0.93). All patients had no recurrence of symptoms or radiological findings, and there were no reported new stroke events or other major illness or death during 6-month follow-up. At 6-month follow-up, 67 (70.5\%) patients had a complete functional outcome (grade 0), $9(9.5 \%)$ had a negligible limited function (grade 1), $12(12.6 \%)$ had a mild limited function (grade 2), and 7 (7.4\%) had moderate limited function (grade 3 ). The differences in the demographics and clinical characteristics between patients with PCFS $=0$ and PCFS $>0$ at 6 -month follow-up are shown in Table 3. Compared to those with $\mathrm{PCFS}=0$, patients with PCFS $>0$ trended to be younger (60 [49-69] vs 64 [56-69], $\mathrm{p}=0.164)$, more likely to had onset symptoms of muscle or joint pain $(9$ [32.1\%] vs 7 [10.4\%], $\mathrm{p}=0.01$ ), and had shorter onset-admission delay (9 days [6-18] vs 14 [10-20], $\mathrm{p}=0.04$ ).

In univariable logistic regression analysis, onset symptoms of muscle or joint pain (unadjusted OR 4.06, 95\% CI 1.33-12.37) were associated with an increased risk of having a PCFS $>0$ at 6 -month follow-up. We found a negative association between the onset-admission delay and a PCFS $>0$ at six-month follow-up (unadjusted OR 0.95, 95\% CI 0.89-1.00). After adjustment for age, onset symptoms of muscle or joint pain (adjusted OR 4.07 95\% CI $1.32-12.54, \mathrm{p}=0.015)$ remained significantly associated with an increased risk of having a PCFS $>0$ at 6 -month follow-up. In the multivariable regression analysis, onset symptoms of muscle or joint pain remained significantly associated with an increased risk of incomplete functional status (adjusted OR 3.39 95\% CI 1.06-10.81, $\mathrm{p}=0.039$ ). The association between the onset-admission delay and having a PCFS $>0$ was lost in the multivariable regression model (Table 4).

To be representative for patients with non-severe COVID 19, we performed a separate analysis by limited on those without severe COVID-19 $(\mathrm{n}=82)$. Additional file 1: Table S1 summarizes the differences in baseline characteristics between patients with and without incomplete functional status at six-month follow-up. This separate analysis did not alter the association between joint or muscle pain and incomplete function. (unadjusted OR 4.0, 95\% CI 1.21-13.18, $\mathrm{p}=0.023$, age-adjusted OR 4.14, 95\% CI 1.23-13.90, $\mathrm{p}=0.022$, multivariate OR $3.46,95 \%$ CI 0.99-12.07, $\mathrm{p}=0.05$ ).

\section{Discussion}

The most important finding of the present study was that a small proportion of COVID-19 survivors may have an incomplete function status at a six-month follow-up after discharge. A previous study found that a considerable proportion of COVID-19 survivors without critical 
Table 3 Baseline characteristics between COVID-19 survivors with complete and incomplete functional status at 6-months follow-up

\begin{tabular}{|c|c|c|c|}
\hline & $\begin{array}{l}\text { Complete function } \\
(n=67)\end{array}$ & $\begin{array}{l}\text { Incomplete function } \\
(n=28)\end{array}$ & $\mathrm{p}$-value \\
\hline Age, (y) median, (IQR) & $64(56-69)$ & $60(49-69)$ & 0.164 \\
\hline Male, n (\%) & $35(52.2)$ & $15(53.6)$ & 0.906 \\
\hline Current smoker, n (\%) & $6(9.0)$ & $4(14.3)$ & 0.685 \\
\hline Regular drinker, n (\%) & $1(1.5)$ & $1(3.6)$ & $>0.999$ \\
\hline Hypertension, n (\%) & $20(29.9)$ & $7(25.0)$ & 0.633 \\
\hline Diabetes, n (\%) & $10(14.9)$ & $4(14.3)$ & $>0.999$ \\
\hline COPD, n (\%) & $5(7.5)$ & $1(3.6)$ & 0.667 \\
\hline Cardio-cerebrovascular disease, n (\%) & $8(11.9)$ & $4(14.3)$ & $>0.999$ \\
\hline Tumor, n (\%) & $4(6.0)$ & $3(10.7)$ & 0.707 \\
\hline Immunosuppressives, n (\%) & $1(1.5)$ & $1(3.6)$ & $>0.999$ \\
\hline Renal impairment, n (\%) & $10(14.9)$ & $1(3.6)$ & 0.220 \\
\hline Wet market exposure, n (\%) & $1(1.5)$ & $0(0)$ & $>0.999$ \\
\hline \multicolumn{4}{|l|}{ Clinical symptoms } \\
\hline Fever, n (\%) & $48(71.6)$ & $21(75.0)$ & 0.738 \\
\hline Dry cough, n, (\%) & $44(65.7)$ & $18(64.3)$ & 0.897 \\
\hline Productive cough, n (\%) & $7(10.4)$ & $4(14.3)$ & 0.856 \\
\hline Fatigue, n (\%) & $25(37.3)$ & $10(35.7)$ & 0.883 \\
\hline Muscle or joint ache, n (\%) & $7(10.4)$ & $9(32.1)$ & 0.010 \\
\hline Thoracalgia, n (\%) & $10(14.9)$ & $6(21.4)$ & 0.440 \\
\hline Sore throat, n (\%) & $11(16.4)$ & $3(10.7)$ & 0.691 \\
\hline Diarrhea, n (\%) & $8(11.9)$ & $1(3.6)$ & 0.376 \\
\hline Catarrh, n (\%) & $3(4.5)$ & $2(7.1)$ & 0.979 \\
\hline Anorexia, n (\%) & $18(26.9)$ & $10(35.7)$ & 0.388 \\
\hline Short of breath, n (\%) & $22(32.8)$ & $11(39.3)$ & 0.547 \\
\hline Headache, n (\%) & $11(16.4)$ & $3(10.7)$ & 0.691 \\
\hline \multicolumn{4}{|l|}{ Routine blood examinations } \\
\hline Decreased leucocytes, n (\%) & $5(7.5)$ & $0(0)$ & 0.317 \\
\hline Decreased lymphocytes, n (\%) & $19(28.4)$ & $8(28.6)$ & 0.983 \\
\hline Decreased hemoglobin, n (\%) & $17(25.4)$ & $7(25.0)$ & 0.970 \\
\hline Decreased platelets, n (\%) & $3(4.5)$ & $2(7.1)$ & 0.979 \\
\hline ALT or AST $>40 U / L$ & $24(35.8)$ & $9(32.1)$ & 0.731 \\
\hline \multicolumn{4}{|l|}{ Chest CT findings, n (\%) } \\
\hline Unilateral pneumonia, n (\%) & $13(19.4)$ & $3(10.7)$ & \\
\hline Bilateral pneumonia, n (\%) & $36(53.7)$ & $19(67.9)$ & \\
\hline Multiple mottling and Ground-glass opacity, n (\%) & $18(26.9)$ & $6(21.4)$ & 0.407 \\
\hline Treated with steroid, $\mathrm{n}(\%)$ & $9(13.4)$ & $1(3.6)$ & 0.289 \\
\hline Antiviral, n (\%) & $66(98.5)$ & $27(96.4)$ & $>0.999$ \\
\hline Severe COVID-19, n (\%) & $10(14.9)$ & $3(10.7)$ & 0.828 \\
\hline Onset to admission, (day) median, (IQR) & $14[10-20]$ & $9[6-18]$ & 0.04 \\
\hline
\end{tabular}

Decreased means below the lower limit of the normal range. Leucocytes $\left(\times 10^{9} / \mathrm{L}\right.$; normal range $\left.3.5-9.5\right)$; Lymphocytes $\left(\times 10^{9} / \mathrm{L} ;\right.$ normal range $\left.1.1-3.2\right)$; Platelets $\left(\times 10^{9} / \mathrm{L}\right.$; normal range 125.0-350.0); Hemoglobin ( $\mathrm{g} / \mathrm{L}$; normal range $\left.130.0-175.0\right)$

COVID-19 coronavirus disease 2019; SD standard deviation; COPD chronic obstructive pulmonary disease; IQR interquartile range; $A L T$ alanine transaminase (U/L; normal range 0-40); AST alanine aminotransferase (U/L; normal range 0-40); CT computed tomography

cases still had radiological and physiological abnormalities at three months after discharge [21]. Our study adds to findings of the previous study by incorporating insights into the functional outcome with a longer-term follow-up data. Several recently published literatures showed that a majority of COVID-19 survivors experienced COVID-19 related symptoms or functional limitations up to six months [22-24]. Different populations and assessing methods may account for the discrepancies among different studies. For example, one study 
Table 4 Risk factors for incomplete function status at 6-months follow-up

\begin{tabular}{|c|c|c|c|c|c|c|}
\hline & \multicolumn{2}{|l|}{ Univariable } & \multicolumn{2}{|l|}{ Age-adjusted } & \multicolumn{2}{|l|}{ Multivariable } \\
\hline & OR $(95 \% \mathrm{Cl})$ & p-value & OR $(95 \% \mathrm{Cl})$ & p-value & OR $(95 \% \mathrm{Cl})$ & $p$-value \\
\hline Age & $0.98[0.95-1.01]$ & 0.219 & - & - & $0.98[0.95-1.02]$ & 0.259 \\
\hline Muscle or joint pain & $4.06[1.33-12.37]$ & 0.014 & $4.07[1.32-12.54]$ & 0.015 & $3.39[1.06-10.81]$ & 0.039 \\
\hline Admission delay & $0.95[0.89-1.00]$ & 0.061 & $0.95[0.89-1.00]$ & 0.065 & $0.96[0.90-1.02]$ & 0.163 \\
\hline
\end{tabular}

Categorical variables are defined as $1=$ yes, $0=$ no

also included patients with suspect COVID-19 assessed using an online panel [24], whereas trained physicians conducted a face-to-face interview in another study [22]. More studies with a longer follow-up are needed to better understand the important question for clinicians and the public: will patients recovered from COVID-19 have long-term sequelae?

In our cohort, COVID-19 survivors with the onset symptoms of joint or muscle pain were at an increased risk of having incomplete function status at six-month after discharge. In line with our finding, a previous study of 158 hospitalized COVID-19 patients showed that the symptoms of muscle or joint pain were significantly associated with the trend of intensification of COVID-19 $(3 / 30 \%$ vs $3 / 128, p=0.048)$ [25]. The associated muscle pain is one of the most frequent causes of pain in SARS$\mathrm{nCoV}-2$ infection. For example, a previous meta-analysis of ten observational studies showed that nearly $36 \%$ of COVID-19 patients had myalgia as one of the most common onset symptoms [26]. Although previous studies have suggested that the onset symptoms of muscle pain do not seem to increase with COVID-19 severity [3, 16, 27], in patients with abnormal chest radiographic findings, myalgia appeared to be an important risk factor for the severity of the overall disease [28]. The upregulation of the proinflammatory cytokines such as interleukin- 6 during viral infection may cause muscle and joint pain [29]. Some researchers believe that myalgia in COVID19 patients might mirror the systematic inflammation and cytokine response [30]. As SARS-CoV-2 infection induces robust immunologic complications like cytokine storm, elevated cytokine levels such as interleukin-6, interleukin-10, and tumor necrosis factor- $\alpha$ might occur, especially in patients with a moderate or severe disease course [31,32]. This hypothesis was supported by a previous observational study that showed COVID-19 patients with muscle injury had manifestations of increased inflammatory response and blood coagulation function [33]. Although our study cannot provide comparative data to determine the effects of COVID-19 on the longterm functional outcome, our findings will contribute to determining COVID-19 at initial stages and suggesting medical intervention in a timely manner.
Our data suggest that the inter-rater reliability of the PCFS interview was satisfactory. Moreover, both raters reported no significant difficulties with scale interpretation, indicating that the PCFS is a simple and feasible approach to monitor the course of symptoms and the impact of symptoms on the functional status of COVID-19 survivors. Previous studies have shown that the functional impairment checklist is reliable, valid and responsive to changes in symptom and disability as a consequence of SARS, suggesting it may provide a means of assessing health-related quality of life outcomes in a longitudinal follow-up [34].

\section{Limitation}

First, this is a small sample-sized retrospective observational study without a predefined protocol. Due to the likely self-selection bias by covering only those undergo the post-COVID-19 survey, our findings need to be interpreted with caution and validated in further large-sample studies. Second, since most of our cohort did not experience severe COVID-19, our findings may not be generalized for patients with severe COVID-19. Third, although we only included patients with complete baseline functional status in our final analysis, we cannot ensure that the functional decline was due to COVID-19. However, when responded to Q3 (Do you suffer from symptoms, pain, depression or anxiety?) our patients reported these symptoms are caused by or mostly related to COVID-19. Fourth, we did not validate the PCFS assessment with other well-validated tools such as six-minutes walking exercise and SaintJeorge respiratory scale. Several recent studies have shown that the PCFS is a validated scale for evaluating 3 to 6-month functional outcomes in COVID-19 patients $[24,35]$. Future studies are needed to benchmark PCFS with other validated tools in Chinese COVID-19 patients. Results from the LEOSS registry (Lean European Open Survey on SARS-CoV-2 Infected Patients; https://LEOSS.net) will better address the long-term functional outcomes. 


\section{Conclusions}

The present study indicated that a small proportion of COVID-19 survivors may have incomplete function status at six-month follow-up, and the risk of incomplete function is higher among patients presenting at baseline with muscle or joint pain. Such patients may benefit from follow-up rehabilitation programs.

\section{Abbreviations}

COVID-19: Coronavirus disease 2019; PCFS: Post-COVID-19 Functional Status Scale; SARS-CoV-2: Severe acute respiratory syndrome coronavirus 2; RT-PCR: Reverse transcription-polymerase chain reaction; MERS: Middle East respiratory syndrome.

\section{Supplementary Information}

The online version contains supplementary material available at https://doi. org/10.1186/s12879-021-06970-3.

Additional file 1: Table 1. Baseline characteristics between COVID-19 non-severe survivors with complete and incomplete functional status at 6-months follow-up.

\section{Acknowledgements}

We thank all the patients with their data for the present study. We thank the medical workers who are on the front line of caring for patients.

\section{Authors' contributions}

HWD and NL had full access to all of the data in the study and take responsibility for the integrity of the data and the accuracy of the data analysis. HWD, SFF, SRW and XLC contributed equally to this work. Study concept and design: HWD and NL. Acquisition, analysis, or interpretation of data: HWD, SFF, SRW, XLC, JNC, XBP, HHL and NL. Drafting of the manuscript: HWD, SFF, XLC, SRW, and NL. Critical revision of the manuscript for important intellectual content: JNC, XBP, YXZ, HYH, RHC, ZYZ, HLL, LL and LMC. Statistics: XQL and PCX. All authors read and approved the final version of the manuscript.

\section{Funding}

This study was supported by the Fujian Science and Technology Innovation Joint Fund Project (Grant No. 2019Y9099), Fujian Provincial Natural and Science Innovation Project (Grant No. 2016B014), and the Young Teacher's Foundation of Fujian Provincial Department of Education (Grant No. JAT190183). The funders had no role in the study design and the collection, analysis, and interpretation of data or drafting of the article and the decision to submit it for publication. The researchers confirm their independence from the funder.

\section{Availability of data and materials}

The datasets generated during and/or analyzed during the current study are available from the corresponding author at xieheliunan1984@fjmu.edu.cn on reasonable request.

\section{Declarations}

\section{Ethics approval and consent to participate}

This study was approved by the Ethics Committee of Fujian Medical University Union Hospital, a member of the National Medical Team Support Wuhan for COVID-19. The administrative permissions were not required to access the raw data, as it is all anonymized data. All clinical investigations were conducted in accordance with the principles expressed in the declaration of Helsinki. Written informed consent was waived due to the nature of our retrospective study of routine baseline clinical data. The patients were asked to give verbal consent before responding to the raters in view of a six-month follow-up of data. Due to the COVID-19 pandemic limitation, it is more convenient for patients to give verbal consent. Therefore, the ethics committee approved the procedure for verbal consent.

\section{Consent for publication}

Not applicable.

\section{Competing interests}

None.

\section{Author details}

${ }^{1}$ Department of Neurology, Fujian Medical University Union Hospital, 29 Xinquan Road, Gulou District, Fuzhou 35000, China. ${ }^{2}$ Institute of Clinical Neurology, Fujian Medical University, Fuzhou, China. ${ }^{3}$ Department of Infectious Disease, Fujian Medical University Union Hospital, Fuzhou, China. ${ }^{4}$ Department of Critical Care Medicine, Fujian Medical University Union Hospital, Fuzhou, China. ${ }^{5}$ Department of Rehabilitation, Fujian Medical University Union Hospital, Fuzhou, China. ${ }^{6}$ Department of Critical Care Medicine, Fujian Provincial Hospital South Branch, Fuzhou, China. ${ }^{7}$ Fujian Center for Disease Control and Prevention, Fuzhou, China. ${ }^{8}$ Department of Radiology, Fujian Medical University Union Hospital, Fuzhou, China. ${ }^{9}$ Department of Respiratory Medicine, Fujian Medical University Union Hospital, Fuzhou, China.

Received: 3 December 2020 Accepted: 10 December 2021

Published online: 20 December 2021

\section{References}

1. Zhou F, Yu T, Du R, Fan G, Liu Y, Liu Z, et al. Clinical course and risk factors for mortality of adult inpatients with covid-19 in Wuhan, China: a retrospective cohort study. Lancet. 2020;395:1054-62.

2. Hopkins J. Johns hopkins coronavirus resource center. https://coron avirus.Jhu.Edu/map.html. Accessed 9 September 2021.

3. Guan WJ, Ni ZY, Hu Y, Liang WH, Ou CQ, He JX, et al. Clinical characteristics of coronavirus disease 2019 in China. N Engl J Med. 2020;382:1708-20.

4. Argenziano MG, Bruce SL, Slater CL, Tiao JR, Baldwin MR, Barr RG, et al. Characterization and clinical course of 1000 patients with coronavirus disease 2019 in New York: retrospective case series. BMJ. 2020;369:m1996.

5. Lechien JR, Chiesa-Estomba CM, Place S, Van Laethem Y, Cabaraux P, Mat Q, et al. Clinical and epidemiological characteristics of 1420 European patients with mild-to-moderate coronavirus disease 2019. J Intern Med. 2020;288:335-44.

6. Hu R, Jiang Z, Gao H, Huang D, Jiang D, Chen F, et al. Recurrent positive reverse transcriptase-polymerase chain reaction results for coronavirus disease 2019 in patients discharged from a hospital in china. JAMA Netw Open. 2020;3:e2010475.

7. Ye G, Pan Z, Pan Y, Deng Q, Chen L, Li J, et al. Clinical characteristics of severe acute respiratory syndrome coronavirus 2 reactivation. J Infect. 2020:80:e14-7.

8. Huang Y, Zhao N. Generalized anxiety disorder, depressive symptoms and sleep quality during COVID-19 outbreak in China: a web-based crosssectional survey. Psychiatry Res. 2020;288:112954.

9. Li X, Dai T, Wang H, Shi J, Yuan W, Li J, et al. Clinical analysis of suspected COVID-19 patients with anxiety and depression. Zhejiang Da Xue Xue Bao Yi Xue Ban. 2020;49:203-8.

10. Gentile F, Aimo A, Forfori F, Catapano G, Clemente A, Cademartiri F, et al. COVID-19 and risk of pulmonary fibrosis: the importance of planning ahead. Eur J Prev Cardiol. 2020;27:1442-6.

11. Spagnolo P, Balestro E, Aliberti S, Cocconcelli E, Biondini D, Casa GD, et al. Pulmonary fibrosis secondary to COVID-19: a call to arms? Lancet Respir Med. 2020:8:750-2.

12. Huang Y, Tan C, Wu J, Chen M, Wang Z, Luo L, et al. Impact of coronavirus disease 2019 on pulmonary function in early convalescence phase. Respir Res. 2020;21:163.

13. Hui DS, Joynt GM, Wong KT, Gomersall CD, LiTS, Antonio G, et al. Impact of severe acute respiratory syndrome (SARS) on pulmonary function, functional capacity and quality of life in a cohort of survivors. Thorax. 2005;60:401-9.

14. Das KM, Lee EY, Singh R, Enani MA, Al Dossari K, Van Gorkom K, et al. Follow-up chest radiographic findings in patients with MERS-CoV after recovery. Indian J Radiol Imaging. 2017;27:342-9.

15. Du HW, Chen JN, Pan XB, Chen XL, Zhang YX, Fang SF, et al. Prevalence and outcomes of re-positive nucleic acid tests in discharged COVID- 19 
patients. Eur J Clin Microbiol. 2021;40:413-7. https://doi.org/10.1007/ s10096-020-04024-1.

16. Du H, Pan X, Liu N, Chen J, Chen X, Werring DJ, et al. The effect of vascular risk factor burden on the severity of COVID-19 illness, a retrospective cohort study. Respir Res. 2020;21:241. https://doi.org/10.1186/ s12931-020-01510-0.

17. World Health Organization. Clinical management of severe acute respiratory infection when novel coronavirus ( $\mathrm{nCoV}$ ) infection is suspected: interim guidance. January 28, 2020. Accessed March 5, 2020.

18. China National Health Commission. New coronavirus pneumonia prevention and control program (7th edn, in Chinese). 2020. http://www.nhc. gov.cn/yzygj/s7653p/202003/46c9294a7dfe4cef80dc7f5912eb1989. shtml. Accessed 3 March 2020.

19. Klok FA, Boon GJAM, Barco S, Endres M, Geelhoed JJM, Knauss S, et al. The Post-COVID-19 Functional Status scale: a tool to measure functional status over time after COVID-19. Eur Respir J. 2020;56:2001494. https:// doi.org/10.1183/13993003.01494-2020.

20. Manual to the Post-COVID-19 Functional Status Scale for physicians and study personnel - including corresponding structured interview and assessment tools. https://osf.io/qgpdv/

21. Zhao YM, Shang YM, Song WB, Li QQ, Xie H, Xu QF, et al. Follow-up study of the pulmonary function and related physiological characteristics of COVID-19 survivors three months after recovery. EClinicalMedicine. 2020;25:100463.

22. Huang C, Huang L, Wang Y, Li X, Ren L, Gu X, et al. 6-month consequences of COVID-19 in patients discharged from hospital: a cohort study. Lancet. 2021;16(397):220-32.

23. Delbressine JM, Machado FVC, Goërtz YMJ, Van Herck M, Meys R, HoubenWilke S, et al. The impact of post-COVID-19 syndrome on self-reported physical activity. Int J Environ Res Public Health. 2021;3(18):6017. https:// doi.org/10.3390/ijerph18116017.

24. Vaes AW, Goërtz YMJ, Van Herck M, Machado FVC, Meys R, Delbressine JM, et al. Recovery from COVID-19: a sprint or marathon? 6-month follow-up data from online long COVID-19 support group members. ERJ Open Res. 2021;24(7):00141-2021. https://doi.org/10.1183/23120541.00141-2021.

25. Li L, Sun W, Han M, Ying Y, Wang Q. A study on the predictors of disease severity of COVID-19. Med Sci Monit. 2020;26: e927167. https://doi.org/ 10.12659/MSM.927167.

26. Li L, Huang T, Wang Y, Wang Z, Liang Y, Huang T, et al. COVID-19 patients' clinical characteristics, discharge rate, and fatality rate of meta-analysis. J Med Virol. 2020;92:577-83.

27. Wu C, Chen X, Cai Y, Xia J, Zhou X, Xu S, et al. Risk factors associated with acute respiratory distress syndrome and death in patients with coronavirus disease 2019 pneumonia in Wuhan, China. JAMA Intern Med. 2020;180:934-43.

28. Zhang X, Cai H, Hu J, Lian J, Gu J, Zhang S, et al. Epidemiological, clinical characteristics of cases of SARS-CoV- 2 infection with abnormal imaging findings. Int J Infect Dis. 2020;94:81-7.

29. Manjavachi MN, Motta EM, Marotta DM, Leite DFP, Calixto JB. Mechanisms involved in IL-6-induced muscular mechanical hyperalgesia in mice. Pain. 2010;151:345-55.

30. Jiang X, Coffee M, Bari A, Wang J, Jiang X, Huang J, et al. Towards an artificial intelligence framework for data-driven prediction of coronavirus clinical severity. Comput Mater Contin. 2020;63:537-51.

31. Chen G, Wu D, Guo W, Cao Y, Huang D, Wang H, et al. Clinical and immunological features of severe and moderate coronavirus disease 2019. J Clin Investig. 2020;130:2620-9.

32. Jamilloux Y, Henry T, Belot A, Viel S, Fauter M, El Jammal T, et al. Should we stimulate or suppress immune responses in COVID-19? Cytokine and anti-cytokine interventions. Autoimmun Rev. 2020;19:102567.

33. Mao L, Jin H, Wang M, Hu Y, Chen S, He Q, et al. Neurologic manifestations of hospitalized patients with coronavirus disease 2019 in Wuhan, China. JAMA Neurol. 2020;77:683-90.

34. Lam SP, Tsui E, Chan KS, Lam CL, So HP. The validity and reliability of the functional impairment checklist (FIC) in the evaluation of functional consequences of severe acute respiratory distress syndrome (SARS). Qual Life Res. 2006;15:217-31.

35. Machado FVC, Meys R, Delbressine JM, Vaes AW, Goërtz YMJ, van Herck $\mathrm{M}$, et al. Construct validity of the post-COVID-19 Functional Status Scale in adult subjects with COVID-19. Health Qual Life Outcomes. 2021;19:40. https://doi.org/10.1186/s12955-021-01691-2.

\section{Publisher's Note}

Springer Nature remains neutral with regard to jurisdictional claims in published maps and institutional affiliations.
Ready to submit your research? Choose BMC and benefit from:

- fast, convenient online submission

- thorough peer review by experienced researchers in your field

- rapid publication on acceptance

- support for research data, including large and complex data types

- gold Open Access which fosters wider collaboration and increased citations

- maximum visibility for your research: over $100 \mathrm{M}$ website views per year

At BMC, research is always in progress.

Learn more biomedcentral.com/submissions 